\title{
A cross-sectional survey assessing factors associated with reading cancer screening information: previous screening behaviour, demographics and decision-making style
}

\author{
Alex Ghanouni, Cristina Renzi and Jo Waller *
}

\begin{abstract}
Background: There is broad agreement that cancer screening invitees should know the risks and benefits of testing before deciding whether to participate. In organised screening programmes, a primary method of relaying this information is via leaflets provided at the time of invitation. Little is known about why individuals do not engage with this information. This study assessed factors associated with reading information leaflets provided by the three cancer screening programmes in England.

Methods: A cross-sectional survey asked screening-eligible members of the general population in England about the following predictor variables: uptake of previous screening invitations, demographic characteristics, and 'decision-making styles' (i.e. the extent to which participants tended to make decisions in a way that was avoidant, rational, intuitive, spontaneous, or dependent). The primary outcome measures were the amount of the leaflet that participants reported having read at their most recent invitation, for any of the three programmes for which they were eligible. Associations between these outcomes and predictor variables were assessed using binary or ordinal logistic regression.

Results: After exclusions, data from 275, 309, and 556 participants were analysed in relation to the breast, cervical, and bowel screening programmes, respectively. Notable relationships included associations between regularity of screening uptake and reading (more of) the information leaflets for all programmes (e.g. odds ratio: 0.16 for participants who never/ very rarely attended breast screening vs. those who always attended previously; $p=.009$ ). Higher rational decision-making scores were associated with reading more of the cervical and bowel screening leaflets (OR: 1.13, $p<.0005$ and OR: 1.11, $p=.045$, respectively). Information engagement was also higher for White British participants compared with other ethnic groups for breast (OR: 3.28, $p=.008)$ and bowel (OR: 2.58, $p=.015)$ information; an opposite relationship was observed for older participants (OR: 0.96, $p=.048$; OR: 0.92, $p=.029$ ).

Conclusions: Interventions that increase screening uptake may also increase subsequent engagement with information. Future research could investigate how to improve engagement at initial invitations. There may also be scope to reduce barriers to accessing non-English information and alternative communication strategies may benefit participants who are less inclined to weigh up advantages and disadvantages as part of their decision-making.
\end{abstract}

Keywords: Cancer screening, Population screening, Public education, Decision making, Informed choice, Survey, England

* Correspondence: j.waller@ucl.ac.uk

Health Behaviour Research Centre, Department of Epidemiology and Public

Health, University College London, Gower Street, London WC1E 6BT, UK 


\section{Background}

Public health policymakers, academics, and practitioners broadly accept the principle that cancer screening invitees should be able to consider the risks and benefits of being tested and make informed decisions about their participation [1-3]. In the UK, the primary method by which organised National Health Service (NHS) cancer screening programmes aim to achieve this is via information leaflets, generally posted to eligible individuals alongside an invitation to have a test (typically mammography for breast screening, cytology or human papillomavirus testing for cervical screening, or stool testing for bowel screening [4-6]).

The national scale of cancer screening programmes means that mailed leaflets can be the only practical method of communicating with all invitees, which amounts to millions of people every year. Consequently, an important outcome related to informed choice is the extent to which screening invitees read this information as it is often a prerequisite for achieving a satisfactory level of understanding. In addition, invitees who do not read screening information and are not screened are unlikely to have made an informed decision not to participate. These individuals may miss out on the health benefits of screening as a result of their lack of engagement.

Previous research on screening information has often focused on its content and quality (e.g. [7]), whereas the extent to which people engage with this information is relatively understudied. Recent work suggests that lack of engagement is a significant barrier to informed choice: Kobayashi et al. [8] report that approximately $20 \%$ of individuals eligible for bowel cancer screening in England have never read any of the associated leaflet and this figure is $63 \%$ among those eligible who had never been screened (vs. $4 \%$ of individuals who had been screened at least once). Non-white individuals are also less likely to have read any of the information leaflet. However, there may be other important factors associated with information engagement that have not so far been investigated. For example, unmarried individuals have lower screening uptake than married individuals [9-11], as do those who do not already know someone diagnosed with cancer [12-17]; this may imply a lesser degree of engagement with information materials in these groups.

Psychological factors may also be associated with (not) reading the leaflet, such as how people tend to make important decisions. One of the most commonly used methods of categorising "decision-making styles" (DMS) is based on five dimensions (avoidant, dependent, intuitive, rational, and spontaneous [18]) and it is plausible that more rational individuals (those who tend to weigh up the advantages and disadvantages before making a decision) are more likely to read information that is designed to be concordant with this way of thinking, whereas the opposite may be true for more avoidant individuals (those who tend to procrastinate before making decisions). DMS may suggest opportunities for improving informed choice in the context of cancer screening although, to our knowledge, they have not previously been investigated. For example, if more dependent individuals (those who rely on others when making decisions) are less likely to read information, they may benefit from greater involvement of people they trust (e.g. healthcare professionals) in order to provide screening information effectively.

We used a large survey of the general population to explore the extent to which screening behaviour, demographic characteristics, and DMS were associated with reading information leaflets for the breast, cervical, and bowel cancer screening programmes in England.

\section{Method \\ Design}

Data were collected as part of the Attitudes, Behaviour and Cancer UK Survey (ABACUS; wave 3) in April and May, 2016. A market research agency (Taylor Nelson Sofres; TNS) collected data during a weekly omnibus survey via face-to-face computer-assisted interviews.

\section{Participants}

Following institutional ethical approval, recruitment was carried out in England using random location sampling based on Census statistics and the Postcode Address File. Quotas were set for key demographic characteristics (e.g. gender and employment status) to obtain a nationally representative sample. Interviews were carried out with a total of 2111 individuals aged $18-70$ years in their homes, following their verbal consent to participate (in accordance with standard survey methodology, responding to questions constituted consent).

\section{Measures \\ Demographics}

Basic demographic data were collected regarding participants' gender, marital status, ethnicity, highest level of education qualification obtained, social class grade, and age. Participants were also asked to indicate i) whether they knew anyone who had been diagnosed with cancer and ii) whether they had been diagnosed with cancer themselves; those that had were asked to state which organ it affected (bowel, lung, breast, cervix, prostate, or other).

\section{Decision-making styles}

Measures of participants' tendencies towards using particular decision-making styles were preceded with the following information:

"We would like to start by asking you some questions about how you make important decisions. I am going 
to read out some statements describing how individuals go about making important decisions and I would like you to tell me how much you agree or disagree with each one."

This was followed by 25 items designed by Scott and Bruce [18], relating to five subscales of decision-making styles and consisting of five items each: 'rational' (e.g. 'My decision-making requires careful thought"), 'intuitive' (e.g. "I generally make decisions that feel right to me"), 'spontaneous' (e.g. "I make quick decisions"), 'avoidant' (e.g. "I postpone decision making whenever possible"), and 'dependent' (e.g. "I rarely make important decisions without consulting other people"). Items were presented in a random order for each participant. Responses were recorded on a fivepoint Likert scale of "strongly disagree" to "strongly agree".

The measure has previously been reported to possess content, concurrent, and construct validity [18]. Acceptable reliability was demonstrated; Cronbach's $\alpha$ was calculated for the five subscales across all participants recruited for this wave of ABACUS and values ranged from 0.72 to 0.80 . Internal consistency could not be substantially improved by omitting items from any subscales.

\section{Screening participation}

Individuals were presented with up to three items relating to their previous screening participation if they met the eligibility criteria for one of the three cancer screening programmes offered by the NHS in England (breast screening: women aged 50-70 years; cervical screening: women aged 25-64 years; bowel screening: men and women aged 60-70 years). These items were omitted if participants were anticipated to find the question upsetting or irrelevant (e.g. they were only asked about previous participation in breast cancer screening if they had not been diagnosed with breast cancer). Items were preceded by text similar to the following:

"The next set of questions are about breast screening. The NHS breast screening programme invites women to have regular mammograms ( $x$-rays of their breasts)."

The first item was based on the Precaution Adoption Process Model [19], a stage model of protective health behaviour. The model categorises people as being in one of seven stages from "unaware" to "maintenance". Participants were asked, "Which one of the following best describes you?", followed by a choice of one of the following response options:

"I have never heard of breast screening/I have heard of breast screening but have never been invited/I have been invited to breast screening but have never been/I have been invited to breast screening but have not been every time I was invited/I have been invited to breast screening and have been every time I was invited"

Participants who stated they had previously been invited but had not been every time were asked whether they had been screened the last time they were invited ("Yes"| "No"I "Don't know") and also asked, "Before the last time you were invited, how regularly had you been going for breast screening?". Response options consisted of:

"Every time I was invited (including if you have only been invited once before your last invitation)/Most times I was invited/Some of the times I was invited/Very rarely or never/I have never been invited before my most recent invitation" (the first option was excluded for participants who had been screened at their last invitation, in order to prevent incompatible responses).

The flow of participants through this section is summarised in Fig. 1.

\section{Reading information leaflets at participants' most recent screening invitation}

Participants who reported having previously been invited to screening were presented with one item based on a previous survey [8]: "When people are invited for breast screening they are sent an NHS leaflet about the screening programme and test. Thinking about the last time when you were invited for cervical screening, how much of the information leaflet did you read?" Response options consisted of: "None of it/Some of it/About half of it/Most of it/ All of it/I don't remember seeing a leaflet".

\section{Piloting}

The survey was piloted using a series of cognitive interviews [20], carried out by the research team with lay members of the public $(n=11)$, to ensure that items were understood as intended and that they did not cause undue participant burden or distress. This was followed by a 'soft-launch' of the survey to a small number of the eligible sample $(n=431)$ by the market research company to determine whether scales had sufficient reliability and that programming was successfully routing participants to all appropriate questions.

\section{Analysis}

Data cleaning and recoding was carried out using SPSS 22 for Windows (IBM, Armonk, NY, USA). Exclusion criteria were ineligibility due to i) gender, ii) age, iii) previous diagnosis of relevant cancer, iv) reporting a non-ordinal highest level of education (e.g. "BTEC/ONC"), and v) reporting not having previously been invited to screening or not having seen an information leaflet. Participants with missing data were also excluded i.e. pertaining to cancer history (theirs 


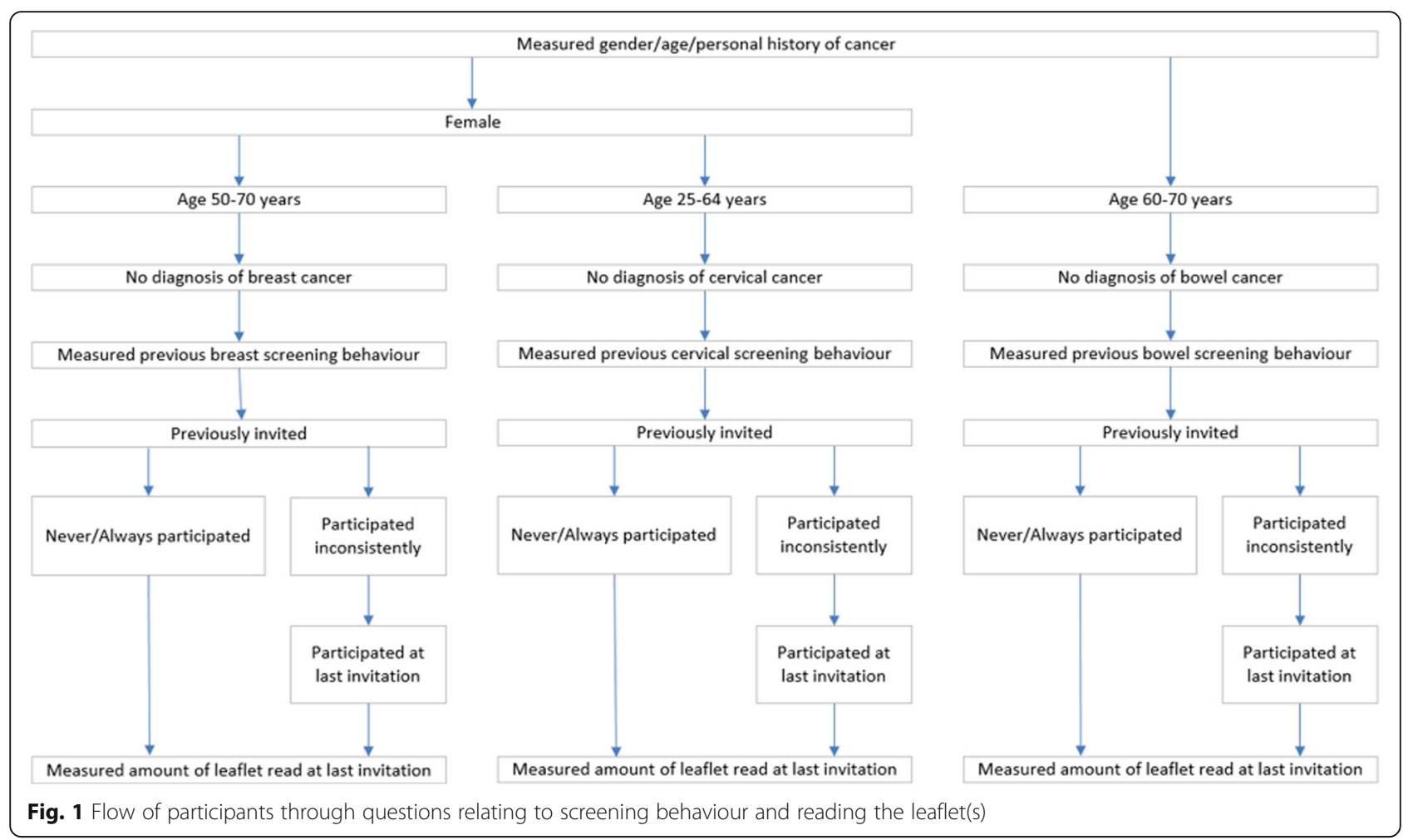

or others they know), decision-making items, screening history, or demographic characteristics. Exclusions due to missing data were limited (7.4\% to $10.4 \%$ of otherwise eligible cases) and hence imputation was not attempted.

Responses to decision-making items were scored from one to five (higher scores representing stronger agreement) and summed for each of the five subscales. Responses to the three items on previous screening history were recoded to form a measure of regularity of screening participation: participants were coded as having very rarely or never participated in screening before their most recent invitation, participated some or most of the time, or always. Highest level of education was categorised based on an approach used by the Office of National Statistics [21]: Qualifications below degree level i.e. "O Levels or GCSE equivalent (Grades D-G)", "O Levels or GCSE equivalent (Grades AC)", "A Levels or Highers", "Higher education below degree" were coded as "Approximately Level 1, 2, or 3", and a university degree or higher i.e. "Bachelor's degree" or "Further degree or higher (e.g. Master's, PhD, etc.)" were coded as "Approximately Level 4". The remaining category was "No formal qualifications". Social class grade was categorised as "Grades A or B", "Grades C1 or C2", and "Grades D or E". Due to the small numbers in each sub-category, ethnicity and marital status were dichotomised ("White British" vs. "Other ethnic groups" and "Married or living as a couple" vs. "Single, widowed, divorced, or separated").

Separate sets of results were generated for the three cancer screening programmes. Descriptive statistics were used to characterise participants eligible for each one. The main hypotheses tested were whether screening behaviour, demographic characteristics, and DMS scores were associated with our outcome of interest, i.e. the amount of the information leaflet that participants had read at their last invitation. The assumption of proportional odds was violated for the analysis of reading the breast leaflet (test of parallel lines: $p<.0005$ ) and a binary logistic regression model was generated for this screening programme, in which the outcome was dichotomised into reading all of the leaflet vs. reading less than all of the leaflet. Sensitivity analyses examined three other possible thresholds for dichotomisation i.e. i) reading all/most of the leaflet vs. reading less; ii) reading all/most/about half the leaflet vs. reading less, and iii) reading at least some of the leaflet vs. reading none of it. The assumption of proportional odds was not rejected for the analysis of reading the cervical $(p=.128)$ or bowel screening leaflets $(p=.376)$ and hence ordinal logistic regression was carried out for these two programmes.

Predictor variables consisted of gender (where applicable), marital status, ethnicity, education, social class grade, personal diagnosis of cancer, knowing someone close with a previous diagnosis of cancer, age, regularity of screening participation (for the relevant programme), and scores on the five DMS subscales. There was little evidence of (multi-)collinearity between independent variables (all Variance Inflation Factors <2.34) and a Box-Tidwell procedure for the model of reading the 
breast screening leaflet showed no violations of the assumption of linearity (all $p$-values $>.240$ ).

Crude proportions (e.g. of White British vs. Other ethnic groups reporting reading each possible amount of the leaflet) and means (and standard deviations; SDs) are reported along with adjusted odds ratios (ORs) for reading all of the leaflet vs. reading less than all of it, or being in a "higher" category of reading the leaflet (e.g. reading some of the leaflet vs. reading less than some or reading most of the leaflet vs. reading less than most), taking into account all predictor variables.

\section{Results}

\section{Participant characteristics}

Table 1, Table 2, and Table 3 describe the main characteristics of participants included in each analysis. Appendix 1 shows the numbers and percentages of participants excluded from the analyses, along with each reason.

\section{Predictors of reading the breast screening information leaflet}

Analysing predictors of reading all (vs. less than all) of the breast screening leaflet showed that white British participants were more likely to have read all the leaflet than participants from other ethnic groups whereas participants who were older or had never or very rarely attended for screening were less likely to have read it all (compared with participants who had always attended). The five DMS did not seem to be associated with reading all (vs. less than all) of the leaflet (Table 1).

The association with regularity of uptake was consistent in all three sensitivity analyses in which the outcome was dichotomised at different thresholds; ORs ranged from 0.12 to 0.19 for never or very rarely vs. always attended and $p$-values ranged from .001 to .004 (for the comparison of these specific levels) and .003 to .014 (for the variable overall). Associations with ethnicity and age were not reproduced: $p$-values ranged from .187 to .464 for ethnicity (ORs ranged from 1.43 to 1.76) and .205 to.705 for age (ORs ranged from 0.97 to 1.01). No additional predictors appeared to be associated in any of the three models (all $p$-values $\geq .082$ ). Full results are included in Appendix 2.

\section{Predictors of reading the cervical screening information leaflet}

Examining predictors of reading (more of) the cervical screening leaflet showed that participants who very rarely or never attended were less likely to have read more of it than those who always attended. Scores on the measure of rational decision-making were also associated with reading the leaflet: participants with higher scores were more likely to have read more of it. There was moderate evidence against the null hypothesis for social class between grades $\mathrm{C} 1$ and $\mathrm{C} 2$ vs. grades D and E. However, there was weak evidence against the null hypothesis for the variable overall and so this was not interpreted to be a true association. There was weak evidence against the null hypothesis for the remaining predictor variables (Table 2).

\section{Predictors of reading the bowel screening information leaflet}

As with the previous analyses, regularity of uptake was associated with reading the leaflet: participants who had never or very rarely attended screening in the past were less likely to have read more of it (vs. those who had always attended). This was also the case for older participants and those with a lower level of education (for both those who had no formal qualifications and those who had approximately Level 1, 2, or 3 qualifications vs. those who had approximately Level 4 qualifications). Participants who knew someone with cancer or were White British were more likely to have read more of the leaflet. There was moderate evidence against the null hypothesis for marital status: participants who were married or living as a couple tended to have read more of the leaflet than others. There was weak evidence against the null hypothesis for other demographic predictors and avoidant, dependent, and intuitive DMS. However, participants with higher rational DMS scores were more likely to have read more of the leaflet and there was moderate evidence against the null hypothesis for the spontaneous DMS with the association in the opposite direction (Table 3).

\section{Discussion}

This study, based on a survey of the screening-eligible general public in England, found consistent relationships between past screening participation and engaging with screening information received at the most recent invitation for all three programmes. Specifically, individuals who had very rarely or never been screened in the past were less likely to have read more (or all) of the most recent information leaflet they received, compared with those who had always been screened. This corresponds with the findings of our previous study, which found those who had never undergone bowel cancer screening were much less likely to have read any of the leaflet (for Faecal Occult Blood testing; only $37 \%$ ) than those who had ever been tested (96\% of whom reported having read at least some of the information). The present results extend these findings by demonstrating similar associations for breast and cervical screening, suggesting that there might be related underlying explanations. It is possible that these associations are related to unmeasured characteristics which lead to both declining screening invitations in the first instance and then disregarding information materials at subsequent invitations (i.e. a general disengagement with screening). Relevant factors could therefore include many of the potential determinants of screening uptake such as fatalism [22], low 
Table 1 Reading breast screening information (women only): descriptive statistics, adjusted ORs, 95\% Cls, $p$-values for variables in the multivariable binary logistic regression model

\begin{tabular}{|c|c|c|c|c|c|c|c|c|}
\hline \multirow[b]{3}{*}{ Characteristic } & \multicolumn{6}{|c|}{ Amount read of the breast screening leaflet: $n(\%) / M(S D)$} & \multirow{3}{*}{$\begin{array}{l}\text { Adjusted } \mathrm{OR}, 95 \% \mathrm{Cl} \\
\text { Read all of the leaflet } \\
\text { (vs. read less than all) }\end{array}$} & \multirow[t]{3}{*}{$p$-value } \\
\hline & None of it & Some of it & About half of it & Most of it & All of it & Total & & \\
\hline & & & & & & & & \\
\hline \multicolumn{9}{|l|}{ Ethnicity } \\
\hline White British & $25(10.2)$ & $37(15.0)$ & $10(4.1)$ & $37(15.0)$ & $137(55.7)$ & 246 & $3.28,1.36$ to 7.89 & .008 \\
\hline vs. Other ethnic groups & $3(10.3)$ & $6(20.7)$ & $3(10.3)$ & $7(24.1)$ & $10(34.5)$ & 29 & & \\
\hline \multicolumn{9}{|l|}{ Marital status } \\
\hline $\begin{array}{l}\text { Married or living as a } \\
\text { couple }\end{array}$ & $15(8.4)$ & $30(16.9)$ & $9(5.1)$ & $29(16.3)$ & $95(53.4)$ & 178 & $0.80,0.45$ to 1.42 & .802 \\
\hline $\begin{array}{l}\text { vs. Single, widowed, } \\
\text { divorced, or separated }\end{array}$ & $13(13.4)$ & $13(13.4)$ & $4(4.1)$ & $15(15.5)$ & $52(53.6)$ & 97 & & \\
\hline Highest level of education & & & & & & & Overall: .150 & \\
\hline No formal qualifications & $11(12.5)$ & $15(17.0)$ & $6(6.8)$ & $20(22.7)$ & $36(40.9)$ & 88 & $0.44,0.19$ to 1.01 & .052 \\
\hline $\begin{array}{l}\text { Approximately Level } 1 \text {, } \\
2 \text {, or } 3\end{array}$ & $13(10.5)$ & $15(12.1)$ & $4(3.2)$ & $21(16.9)$ & $71(57.3)$ & 124 & $0.60,0.29$ to 1.24 & .168 \\
\hline $\begin{array}{l}\text { vs. Approximately } \\
\text { Level } 4\end{array}$ & $4(6.3)$ & $13(20.6)$ & $3(4.8)$ & $3(4.8)$ & $40(63.5)$ & 63 & & \\
\hline Social class grade & & & & & & & Overall: .876 & \\
\hline Grade A or B & $7(11.3)$ & $8(12.9)$ & $4(6.5)$ & $8(12.9)$ & $35(56.5)$ & 62 & $0.90,0.40$ to 2.07 & .811 \\
\hline Grade $\mathrm{C} 1$ or $\mathrm{C} 2$ & $9(7.4)$ & $20(16.5)$ & $6(5.0)$ & $16(13.2)$ & $70(57.9)$ & 121 & $1.08,0.57$ to 2.05 & .811 \\
\hline vs. Grade D or E & $12(13.0)$ & $15(16.3)$ & $3(3.3)$ & $20(21.7)$ & $42(45.7)$ & 92 & & \\
\hline \multicolumn{9}{|l|}{ Personal diagnosis of cancer } \\
\hline Yes & $3(14.3)$ & $1(4.8)$ & $1(4.8)$ & $4(19.0)$ & $12(57.1)$ & 21 & $0.90,0.35$ to 2.35 & .834 \\
\hline vs. No & $25(9.8)$ & $42(16.5)$ & $12(4.7)$ & $40(15.7)$ & $135(53.1)$ & 254 & & \\
\hline \multicolumn{9}{|l|}{$\begin{array}{l}\text { Knows someone with } \\
\text { cancer }\end{array}$} \\
\hline Yes & $21(10.4)$ & $32(15.8)$ & $7(3.5)$ & $29(14.4)$ & $113(55.9)$ & 202 & $1.23,0.69$ to 2.20 & .493 \\
\hline vs. No & $7(9.6)$ & $11(15.1)$ & $6(8.2)$ & $15(20.5)$ & $34(46.6)$ & 73 & & \\
\hline Breast screening regularity & & & & & & & Overall: .014 & \\
\hline $\begin{array}{l}\text { Never or very rarely } \\
\text { attended... }\end{array}$ & $6(35.3)$ & $4(23.5)$ & $2(11.8)$ & $2(11.8)$ & $3(17.6)$ & 17 & $0.16,0.04$ to 0.63 & .009 \\
\hline $\begin{array}{l}\text { Attended some or } \\
\text { most of the time... }\end{array}$ & $1(6.3)$ & $4(25.0)$ & $2(12.5)$ & $3(18.8)$ & $6(37.5)$ & 16 & $0.43,0.14$ to 1.30 & .135 \\
\hline $\begin{array}{l}\text { vs. Always attended } \\
\text { before most recent } \\
\text { invitation }\end{array}$ & $21(8.7)$ & $35(14.5)$ & $9(3.7)$ & $39(16.1)$ & $138(57.0)$ & 242 & & \\
\hline Age (in years) & $60.1(5.7)$ & $61.7(6.4)$ & $59.7(5.5)$ & $62.2(5.4)$ & $59.8(6.1)$ & $60.5(6.0)$ & $0.96,0.92$ to 1.00 & .048 \\
\hline \multicolumn{9}{|l|}{ Decision-making styles } \\
\hline Avoidant score & $12.3(3.6)$ & $14.0(4.2)$ & $14.9(5.2)$ & $12.6(3.2)$ & $12.5(3.6)$ & $12.8(3.8)$ & $0.97,0.89$ to 1.05 & .452 \\
\hline Dependent score & $16.0(3.9)$ & $17.3(3.5)$ & $17.6(4.6)$ & $16.1(4.4)$ & $16.5(3.8)$ & $16.6(3.9)$ & $1.03,0.96$ to 1.11 & .434 \\
\hline Intuitive score & $19.1(2.5)$ & $18.2(2.4)$ & $18.6(3.3)$ & $19.3(2.7)$ & $18.8(2.8)$ & $18.8(2.7)$ & $1.01,0.91$ to 1.12 & .892 \\
\hline Rational score & $19.1(3.0)$ & $20.0(2.0)$ & $19.5(3.0)$ & $19.1(2.9)$ & $19.9(2.9)$ & $19.7(2.8)$ & $1.08,0.97$ to 1.19 & .151 \\
\hline Spontaneous score & $14.9(4.0)$ & $13.4(3.3)$ & $15.2(4.7)$ & $15.2(4.7)$ & $13.8(3.9)$ & $13.9(3.7)$ & $1.03,0.95$ to 1.11 & .528 \\
\hline
\end{tabular}

Adjusted ORs and $95 \%$ Cls are per unit increase in the case of continuous variables; $p$-values <.05 are in bold; all predictor variables are included in the model

(perceived) risk [23, 24], and greater discomfort thinking about cancer [25]. This might imply that interventions aiming to improve screening uptake, specifically, may also have positive effects in terms of reading screening information at subsequent invitations. However, this approach to improving informed choice alone would have flaws, given that invitees would have already been asked to make at least one prior screening decision, which may not have been informed itself. As a result, it may be preferable to investigate how to increase engagement with screening information at 
Table 2 Reading cervical screening information (women only): descriptive statistics, adjusted ORs, 95\% Cls, $p$-values for variables in the multivariable ordinal logistic regression model

\begin{tabular}{|c|c|c|c|c|c|c|c|c|}
\hline \multirow[b]{3}{*}{ Characteristic } & \multicolumn{6}{|c|}{ Amount read of the cervical screening leaflet: $n(\%) / M(S D)$} & \multirow{3}{*}{$\begin{array}{l}\text { Adjusted } \mathrm{OR}, 95 \% \mathrm{Cl} \\
\text { Read more of the leaflet } \\
\text { (i.e. any amount more) }\end{array}$} & \multirow[t]{3}{*}{$p$-value } \\
\hline & None of it & Some of it & About half of it & Most of it & All of it & Total & & \\
\hline & $(n=94 ; 16.9 \%)$ & $(n=108 ; 19.4 \%)$ & $(n=34 ; 6.1 \%)$ & $(n=106 ; 19.1 \%)$ & $(n=214 ; 38.5 \%)$ & $(n=556)$ & & \\
\hline \multicolumn{9}{|l|}{ Ethnicity } \\
\hline White British & $85(19.5)$ & $84(19.3)$ & $19(4.4)$ & $78(17.9)$ & $169(38.9)$ & 435 & $0.79,0.53$ to 1.18 & .248 \\
\hline vs. Other ethnic groups & $9(7.4)$ & $24(19.8)$ & $15(12.4)$ & $28(23.1)$ & $45(37.2)$ & 121 & & \\
\hline \multicolumn{9}{|l|}{ Marital status } \\
\hline Married or living as a couple & $61(16.1)$ & $73(19.3)$ & $25(6.6)$ & $70(18.5)$ & $150(39.6)$ & 379 & $1.11,0.79$ to 1.56 & .558 \\
\hline $\begin{array}{l}\text { vs. Single, widowed, } \\
\text { divorced, or separated }\end{array}$ & $33(18.6)$ & $35(19.8)$ & $9(5.1)$ & $36(20.3)$ & $64(36.2)$ & 177 & & \\
\hline Highest level of education & & & & & & & Overall: .850 & \\
\hline No formal qualifications & $14(19.4)$ & $12(16.7)$ & $4(5.6)$ & $15(20.8)$ & $27(37.5)$ & 72 & $0.92,0.52$ to 1.64 & .784 \\
\hline $\begin{array}{l}\text { Approximately Level } 1 \text {, } \\
2 \text {, or } 3\end{array}$ & $51(17.2)$ & $57(19.3)$ & $19(6.4)$ & $55(18.6)$ & $114(38.5)$ & 296 & $1.06,0.73$ to 1.53 & .770 \\
\hline $\begin{array}{l}\text { vs. Approximately } \\
\text { Level } 4\end{array}$ & $29(15.4)$ & $39(20.7)$ & $11(5.9)$ & $36(19.1)$ & $73(38.8)$ & 188 & & \\
\hline Social class grade & & & & & & & Overall: .142 & \\
\hline Grade A or B & $20(15.4)$ & $29(22.3)$ & $6(4.6)$ & $22(16.9)$ & $53(40.8)$ & 130 & $0.77,0.47$ to 1.26 & .297 \\
\hline Grade $\mathrm{C} 1$ or $\mathrm{C} 2$ & $52(18.1)$ & $59(20.6)$ & $17(5.9)$ & $57(19.9)$ & $102(35.5)$ & 287 & $0.67,0.44$ to 1.00 & .050 \\
\hline vs. Grade D or E & $22(15.8)$ & $20(14.4)$ & $11(7.9)$ & $27(19.4)$ & $59(42.4)$ & 139 & & \\
\hline \multicolumn{9}{|l|}{ Personal diagnosis of cancer } \\
\hline Yes & $4(14.8)$ & $4(14.8)$ & $1(3.7)$ & $4(14.8)$ & $14(51.9)$ & 27 & $1.27,0.60$ to 2.68 & .537 \\
\hline vs. No & $90(17.0)$ & $104(19.7)$ & $33(6.2)$ & $102(19.3)$ & $200(37.8)$ & 529 & & \\
\hline \multicolumn{9}{|l|}{$\begin{array}{l}\text { Knows someone with } \\
\text { cancer }\end{array}$} \\
\hline Yes & $67(18.0)$ & $76(20.4)$ & $20(5.4)$ & $63(16.9)$ & $147(39.4)$ & 373 & $0.87,0.62$ to 1.22 & .420 \\
\hline vs. No & $27(14.8)$ & $32(17.5)$ & $14(7.7)$ & $43(23.5)$ & $67(36.6)$ & 183 & & \\
\hline Cervical screening regularity & & & & & & & Overall: .023 & \\
\hline $\begin{array}{l}\text { Never or very rarely } \\
\text { attended... }\end{array}$ & $14(27.5)$ & $11(21.6)$ & $5(9.8)$ & $6(11.8)$ & $15(29.4)$ & 51 & $0.51,0.30$ to 0.87 & .014 \\
\hline $\begin{array}{l}\text { Attended some or } \\
\text { most of the time... }\end{array}$ & $9(15.5)$ & $12(20.7)$ & $12(20.7)$ & $8(13.8)$ & $17(29.3)$ & 58 & $0.68,0.41$ to 1.12 & .131 \\
\hline $\begin{array}{l}\text { vs. Always attended } \\
\text { before most recent } \\
\text { invitation }\end{array}$ & $71(15.9)$ & $85(19.0)$ & $17(3.8)$ & $92(20.6)$ & $182(40.7)$ & 447 & & \\
\hline Age (in years) & $43.0(10.8)$ & $42.7(11.1)$ & $43.0(11.8)$ & $42.8(11.2)$ & $44.7(11.3)$ & $43.5(11.2)$ & $1.01,1.00$ to 1.03 & .144 \\
\hline \multicolumn{9}{|l|}{ Decision-making styles } \\
\hline Avoidant score & $13.6(4.1)$ & $14.0(3.9)$ & $14.6(4.1)$ & $13.9(3.4)$ & $13.0(3.8)$ & $13.6(3.8)$ & $0.97,0.93$ to 1.02 & .211 \\
\hline Dependent score & $16.8(4.1)$ & $17.4(3.1)$ & $18.0(3.1)$ & $17.0(3.5)$ & $17.0(3.4)$ & $17.1(3.5)$ & $1.00,0.95$ to 1.05 & .984 \\
\hline Intuitive score & $18.9(2.5)$ & $18.8(2.3)$ & $18.5(2.6)$ & $19.0(2.7)$ & $18.7(2.9)$ & $18.7(2.7)$ & $0.99,0.93$ to 1.05 & .663 \\
\hline Rational score & $18.7(3.2)$ & $19.4(2.0)$ & $19.9(2.3)$ & $19.8(2.3)$ & $20.0(2.8)$ & $19.6(2.6)$ & $1.13,1.06$ to 1.21 & $<.0005$ \\
\hline Spontaneous score & $14.8(3.7)$ & $14.2(3.5)$ & $15.4(3.8)$ & $14.7(3.3)$ & $14.2(3.6)$ & $14.5(3.6)$ & $1.02,0.97$ to 1.07 & .466 \\
\hline
\end{tabular}

Adjusted ORs and $95 \%$ Cls are per unit increase in the case of continuous variables; $p$-values $<.05$ are in bold; all predictor variables are included in the model

the first invitation. A further related line of research would be to investigate whether increasing engagement also results in invitees making more informed decisions to take part, with potentially positive effects on population health.

We also found (less consistent) relationships for age and ethnicity, in which older and non-white British participants were less likely to read all (or more) of the bowel and breast screening leaflets. Insofar as these reflect genuine associations (given that they were not replicated in the sensitivity analyses for the breast screening leaflet), they may reflect an effect of the number of invitations that people have received (older people will have been invited more often and may have felt less need to re-read the information) and language barriers (non-white British participants may have 
Table 3 Reading bowel screening information: descriptive statistics, adjusted ORs, 95\% Cls, p-values for variables in the multivariable ordinal logistic regression model

\begin{tabular}{|c|c|c|c|c|c|c|c|c|}
\hline \multirow[b]{3}{*}{ Characteristic } & \multicolumn{6}{|c|}{ Amount read of the bowel screening leaflet: $n(\%) / M(S D)$} & \multirow{3}{*}{$\begin{array}{l}\text { Adjusted } \mathrm{OR}, 95 \% \mathrm{Cl} \\
\text { Read more of the leaflet } \\
\text { (i.e. any amount more) }\end{array}$} & \multirow[t]{3}{*}{$p$-value } \\
\hline & None of it & Some of it & About half of it & Most of it & All of it & Total & & \\
\hline & $(n=13 ; 4.2 \%)$ & $(n=44 ; 14.2 \%)$ & $(n=14 ; 4.5 \%)$ & $(n=63 ; 20.4 \%)$ & $(n=175 ; 56.6 \%)$ & & & \\
\hline \multicolumn{9}{|l|}{ Gender } \\
\hline Male & $8(5.0)$ & $28(17.5)$ & $7(4.4)$ & $31(19.4)$ & $86(53.8)$ & 160 & $0.79,0.50$ to 1.27 & .338 \\
\hline vs. Female (reference category) & $5(3.4)$ & $16(10.7)$ & $7(4.7)$ & $32(21.5)$ & $89(59.7)$ & 149 & & \\
\hline \multicolumn{9}{|l|}{ Ethnicity } \\
\hline White British & $10(3.5)$ & $41(14.5)$ & $11(3.9)$ & $57(20.2)$ & $163(57.8)$ & 282 & $2.58,1.20$ to 5.56 & .015 \\
\hline vs. Other ethnic groups & $3(11.1)$ & $3(11.1)$ & $3(11.1)$ & $6(22.2)$ & $12(44.4)$ & 27 & & \\
\hline \multicolumn{9}{|l|}{ Marital status } \\
\hline Married or living as a couple & $4(1.9)$ & $23(11.1)$ & $10(4.8)$ & $45(21.7)$ & $125(60.4)$ & 207 & $1.65,0.99$ to 2.76 & .056 \\
\hline $\begin{array}{l}\text { vs. Single, widowed, divorced, } \\
\text { or separated }\end{array}$ & $9(8.8)$ & $21(20.6)$ & $4(3.9)$ & $18(17.6)$ & $50(49.0)$ & 102 & & \\
\hline Highest level of education & & & & & & & Overall: .003 & \\
\hline No formal qualifications & $8(7.1)$ & $18(16.1)$ & $5(4.5)$ & $27(24.1)$ & $54(48.2)$ & 112 & $0.30,0.14$ to 0.64 & .002 \\
\hline Approximately Level 1,2 , or 3 & $4(3.2)$ & $21(16.9)$ & $4(3.2)$ & $27(21.8)$ & $68(54.8)$ & 124 & $0.31,0.15$ to 0.40 & .001 \\
\hline vs. Approximately Level 4 & $1(1.4)$ & $5(6.8)$ & $5(6.8)$ & $9(12.3)$ & $53(72.6)$ & 73 & & \\
\hline Social class grade & & & & & & & Overall: .907 & \\
\hline Grade A or B & $3(3.5)$ & $10(11.6)$ & $4(4.7)$ & $13(15.1)$ & $56(65.1)$ & 86 & $0.92,0.45$ to 1.88 & .916 \\
\hline Grade $\mathrm{C} 1$ or $\mathrm{C} 2$ & $5(4.1)$ & $11(9.1)$ & $4(3.3)$ & $32(26.4)$ & $69(57.0)$ & 121 & $1.06,0.61$ to 1.85 & .844 \\
\hline vs. Grade D or E & $5(4.9)$ & $23(22.5)$ & $6(5.9)$ & $18(17.6)$ & $50(49.0)$ & 102 & & \\
\hline \multicolumn{9}{|l|}{ Personal diagnosis of cancer } \\
\hline Yes & $2(5.7)$ & $2(5.7)$ & $2(5.7)$ & $10(28.6)$ & $19(54.3)$ & 35 & $1.18,0.5$ to 2.48 & .662 \\
\hline vs. No & $11(4.0)$ & $42(15.3)$ & $12(4.4)$ & $53(19.3)$ & $156(56.9)$ & 274 & & \\
\hline \multicolumn{9}{|l|}{ Knows someone with cancer } \\
\hline Yes & $8(3.9)$ & $23(11.3)$ & $6(2.9)$ & $37(18.1)$ & $130(63.7)$ & 204 & $1.84,1.13$ to 2.99 & .014 \\
\hline vs. No & $5(4.8)$ & $21(20.0)$ & $8(7.6)$ & $26(24.8)$ & $45(42.9)$ & 105 & & \\
\hline Bowel screening regularity & & & & & & & Overall: $<.0005$ & \\
\hline Never or very rarely attended... & $7(11.3)$ & $14(22.6)$ & $4(6.5)$ & $12(19.4)$ & $25(40.3)$ & 62 & $0.34,0.19$ to 0.59 & $<.0005$ \\
\hline $\begin{array}{l}\text { Attended some or most of } \\
\text { the time... }\end{array}$ & $1(5.3)$ & $2(10.5)$ & $2(10.5)$ & $7(36.8)$ & $7(36.8)$ & 19 & $0.43,0.18$ to 1.04 & .061 \\
\hline $\begin{array}{l}\text { vs. Always attended before } \\
\text { most recent invitation }\end{array}$ & $5(2.2)$ & $28(12.3)$ & $8(3.5)$ & $44(19.3)$ & $143(62.7)$ & 228 & & \\
\hline Age (in years) & $65.5(2.8)$ & $67.3(2.6)$ & $65.8(3.8)$ & $65.8(2.9)$ & $65.4(3.3)$ & $65.8(3.2)$ & $0.92,0.85$ to 0.99 & .029 \\
\hline \multicolumn{9}{|l|}{ Decision-making style } \\
\hline Avoidant score & $13.1(3.1)$ & $13.5(3.9)$ & $13.9(3.8)$ & $13.0(3.5)$ & $12.6(3.4)$ & $12.9(3.5)$ & $0.96,0.89$ to 1.04 & .298 \\
\hline Dependent score & $15.4(4.7)$ & $16.5(3.5)$ & $16.8(4.6)$ & $16.0(4.1)$ & $16.5(3.5)$ & $16.4(3.7)$ & $1.04,0.97$ to 1.11 & .291 \\
\hline Intuitive score & $18.1(3.4)$ & $18.3(2.8)$ & $18.9(2.6)$ & $18.8(2.8)$ & $18.5(2.6)$ & $18.6(2.7)$ & $1.10,1.00$ to 1.22 & .061 \\
\hline Rational score & $18.2(4.0)$ & $19.3(2.9)$ & $19.1(2.1)$ & $19.8(2.2)$ & $20.0(2.1)$ & $19.8(2.4)$ & $1.11,1.00$ to 1.23 & .045 \\
\hline Spontaneous score & $15.5(4.4)$ & $14.5(3.6)$ & $14.9(3.9)$ & $13.5(3.0)$ & $13.2(3.4)$ & $13.6(3.4)$ & $0.93,0.86$ to 1.00 & .051 \\
\hline
\end{tabular}

Adjusted ORs and $95 \% \mathrm{Cls}$ are per unit increase in the case of continuous variables; $p$-values $<.05$ are in bold; all predictor variables are included in the model

been less likely to speak English as a first language and so may have found the information less comprehensible). Although screening information leaflets are available in multiple languages, they are less easy to obtain than the English-language default which is sent with all invitations. However, we did not collect data on the language of leaflets that participants received, or participants' first language, meaning that this may warrant further investigation.

Three possible associations were only observed for the bowel screening leaflet, namely education, knowing someone diagnosed with cancer, and marital status. To some extent, the former result was unexpected, given that no 
such relationship was observed in our previous study [8]. However, there is evidence that a lack of education is associated with lower health literacy [26] and lower health literacy is associated with less information-seeking and greater effort in reading information about bowel cancer screening [27], so it is plausible that these individuals would be less likely to engage with the leaflet. There is also strong prior evidence that uptake of bowel cancer screening is associated with a family history of the disease (e.g. [12-15]), which often translates to a greater personal risk. The present findings might be a reflection of a generalised concern about cancer due to knowing a relative with a diagnosis, translating to greater engagement with screening information. Finally, although there was only moderate evidence against the null hypothesis with respect to marital status, the observation that participants who were married or living as a couple tended to read more of the leaflet than single, widowed, or divorced participants is concordant with the well-established finding that individuals with a partner are also more likely to be screened [9-11]. It may be possible to increase levels of engagement with information leaflets by posting them not only to invitees but also to their partners, along with encouragement to discuss the topic together.

There was little evidence for most hypothesised associations with DMS scores (e.g. that participants with higher avoidance DMS scores being less likely to read more of the leaflets) but there was some evidence to suggest higher spontaneous DMS scores were associated with reading less of the bowel screening leaflet. One speculative explanation is that this relates to the length of the leaflet, which takes time to read and process, making it less attractive to people who prefer to make quick decisions. Rational scores were associated with reading the bowel and cervical leaflets in the intuitive direction, with lower scores being associated with reading less information. The stated aims of the leaflets are e.g. to give "information about bowel cancer, and the benefits and risks of bowel cancer screening... to help [people] make an informed choice about taking part" [6]. This approach may be most acceptable to people who tend to make decisions in this way but it may reduce engagement among those who do not. Consequently, alternative communication strategies may increase engagement with the leaflets among the $23 \%$ of participants who reported reading about half of it or less. For example, although leaflets are designed based on a "consider an offer" approach that reduces the extent to which invitees have to weigh up screening attributes [28], the present findings suggest that reducing it further may be beneficial (e.g. with advice on where to access the omitted material using a "gist" approach; [29]). However, this approach may need to be balanced against arguments that a given level of information is ethically necessary [30].
It is not clear why some findings were not apparent across all three programmes. For example, the association between knowing someone with cancer and reading the leaflet could have been hypothesised for the Breast Screening Programme [16, 17]. However, the criteria for eligibility of the three programmes meant that samples were highly dissimilar in terms of age and gender. The three programmes also differ substantially in terms of e.g. how wellestablished they are and the nature of the target disease, with implications for prior knowledge and risk perceptions.

Limitations relate primarily to the measures used. We were reliant on participants self-reporting the main outcomes and past screening behaviour and these are likely to be vulnerable to social desirability bias and also recall errors, given that they relate to events that occurred up to 5 years ago [31]. This may partially account for differences in the proportion of people reporting reading none of the bowel screening information by Kobayashi et al. (22\% [8]) and in this study (4\%). There were also differences in reported previous screening participation (69\% reported having previously been screened vs. at least $80 \%$ in this study). We also did not determine whether participants had absorbed screening information prior to their most recent invitation, either by reading the information leaflet at a previous invitation or by accessing the relevant information another way (e.g. during a consultation with a primary care provider or via the web), and so had chosen not to (re-)read the leaflet. Furthermore, although previously tested and widely used, it is unclear what the real-world implications are for a given DMS score. Finally, the design of the survey and eligibility criteria resulted in smaller samples for the analyses of reading the breast and bowel screening leaflets, which may have resulted in less accurate estimates of associations [32]. This was considered acceptable as part of an exploratory analysis but would require further evaluation using confirmatory designs.

\section{Conclusions}

This exploratory study found consistent positive associations between regular uptake of screening tests in the past and reading screening information leaflets at subsequent invitations for all programmes. We also found positive associations with younger age, white British ethnicity, higher levels of education, knowing someone diagnosed with cancer, and higher rational and lower spontaneous DMS scores for some screening programmes. Implications of these findings include possible merits of reducing barriers to non-English information, and reducing its length and complexity (with information accessible elsewhere instead). These latter two suggestions may also help make information more accessible to invitees who are less inclined to weigh up risks and benefits of screening. 


\section{Appendix 1}

Table 4 Numbers and percentages of participants excluded from the full sample of 2111 participants, for each analysis of screening information

\begin{tabular}{|c|c|c|c|}
\hline & n (\%) & & \\
\hline Reason for exclusion & Breast & Cervical & Bowel \\
\hline Inapplicable gender & $989(46.8)$ & $989(46.8)$ & N/A \\
\hline Older or younger than eligible age range & $71734.0)$ & $281(13.3)$ & $1647(78.0)$ \\
\hline Previous diagnosis of relevant cancer & $19(0.9)$ & $17(0.8)$ & $2(0.1)$ \\
\hline Non-ordinal highest level of education & $33(1.6)$ & $81(3.8)$ & $55(2.6)$ \\
\hline No previous screening invitation & $35(1.7)$ & $72(3.4)$ & $66(3.1)$ \\
\hline Did not see the screening information leaflet at last invitation & $16(0.8)$ & $57(2.7)$ & $9(0.4)$ \\
\hline Missing data on either dependent or independent variables & $27(1.3)$ & $58(2.7)$ & $23(1.1)$ \\
\hline Total excluded & $1836(87.0)$ & $1555(73.7)$ & $1802(85.4)$ \\
\hline Total analysed & 275 & 556 & 309 \\
\hline
\end{tabular}

\section{Appendix 2}

Table 5 Sensitivity analyses: reading breast screening information (women only): adjusted ORs, 95\% Cls, p-values for variables in binary logistic regression models

\begin{tabular}{|c|c|c|c|c|c|c|c|c|}
\hline \multirow{4}{*}{ Characteristic } & \multicolumn{8}{|c|}{ Amount read of the breast screening leaflet } \\
\hline & \multirow{2}{*}{\multicolumn{2}{|c|}{$\begin{array}{l}\text { Read at least some of } \\
\text { the leaflet } \\
\text { (vs. read none) }\end{array}$}} & \multirow{2}{*}{\multicolumn{2}{|c|}{$\begin{array}{l}\text { Read at least about } \\
\text { half of the leaflet } \\
\text { (vs. read less than } \\
\text { about half) }\end{array}$}} & \multirow{2}{*}{\multicolumn{2}{|c|}{$\begin{array}{l}\text { Read most/all of the } \\
\text { leaflet } \\
\text { (vs. read less than } \\
\text { most/all) }\end{array}$}} & \multirow{2}{*}{\multicolumn{2}{|c|}{$\begin{array}{l}\text { Read all of the leaflet } \\
\text { (vs. read less than all) }\end{array}$}} \\
\hline & & & & & & & & \\
\hline & $\mathrm{OR}, 95 \% \mathrm{Cl}$ & $\mathrm{p}$ & $\mathrm{OR}, 95 \% \mathrm{Cl}$ & $\mathrm{p}$ & $\mathrm{OR}, 95 \% \mathrm{Cl}$ & $p$ & $\mathrm{OR}, 95 \% \mathrm{Cl}$ & $\mathrm{p}$ \\
\hline \multicolumn{9}{|l|}{ Ethnicity } \\
\hline White British & $1.66,0.43$ to 6.46 & .464 & $1.43,0.59$ to 3.47 & .428 & $1.76,0.76$ to 4.10 & .187 & $3.28,1.36$ to 7.89 & .008 \\
\hline \multicolumn{9}{|l|}{ vs. Other ethnic groups } \\
\hline \multicolumn{9}{|l|}{ Marital status } \\
\hline Married or living as a couple & $1.32,0.54$ to 3.23 & .540 & $0.96,0.52$ to 1.80 & .907 & $0.97,0.53$ to 1.78 & .924 & $0.80,0.45$ to 1.42 & .450 \\
\hline \multicolumn{9}{|l|}{$\begin{array}{l}\text { vs. Single, widowed, divorced, } \\
\text { or separated }\end{array}$} \\
\hline Highest level of education & Overall: .452 & & Overall: .913 & & Overall: .791 & & Overall: .150 & \\
\hline No formal qualifications & $0.44,0.10$ to 1.90 & .269 & $1.09,0.44$ to 2.68 & .856 & $0.85,0.36$ to 2.01 & .704 & $0.44,0.19$ to 1.01 & .052 \\
\hline Approximately Level 1, 2, or 3 & $0.44,0.12$ to 1.64 & .222 & $1.18,0.54$ to 2.60 & .683 & $1.07,0.50$ to 2.29 & .861 & $0.60,0.29$ to 1.24 & .168 \\
\hline \multicolumn{9}{|l|}{ vs. Approximately Level 4} \\
\hline Social class grade & Overall: .689 & & Overall: .925 & & Overall: .782 & & Overall: .876 & \\
\hline Grade A or B & $0.73,0.21$ to 2.59 & .631 & $1.18,0.47$ to 2.98 & .731 & $0.77,0.31$ to 1.89 & .565 & $0.90,0.40$ to 2.07 & .811 \\
\hline Grade $\mathrm{C} 1$ or $\mathrm{C} 2$ & $1.23,0.43$ to 3.54 & .706 & $1.01,0.50$ to 2.06 & .977 & $0.79,0.39$ to 1.59 & .508 & $1.08,0.57$ to 2.05 & .811 \\
\hline \multicolumn{9}{|l|}{ vs. Grade D or E } \\
\hline \multicolumn{9}{|l|}{ Personal diagnosis of cancer } \\
\hline Yes & $0.70,0.17$ to 2.84 & .612 & $1.25,0.39$ to 4.04 & .708 & $1.11,0.37$ to 3.32 & .846 & $0.90,0.35$ to 2.35 & .834 \\
\hline \multicolumn{9}{|l|}{ vs. No } \\
\hline \multicolumn{9}{|l|}{ Knows someone with cancer } \\
\hline Yes & $0.66,0.24$ to 1.86 & .435 & $0.71,0.36$ to 1.40 & .328 & $0.90,0.48$ to 1.69 & .750 & $1.23,0.69$ to 2.20 & .493 \\
\hline vs. No & & & & & & & & \\
\hline
\end{tabular}


Table 5 Sensitivity analyses: reading breast screening information (women only): adjusted ORs, 95\% Cls, $p$-values for variables in binary logistic regression models (Continued)

\begin{tabular}{|c|c|c|c|c|c|c|c|c|}
\hline Breast screening regularity & Overall: .008 & & Overall: .014 & & Overall: .003 & & Overall: .014 & \\
\hline Never or very rarely attended.. & $0.12,0.03$ to 0.48 & .003 & $0.19,0.06$ to 0.58 & .004 & $0.14,0.44$ to 0.47 & .001 & $0.16,0.04$ to 0.63 & .009 \\
\hline $\begin{array}{l}\text { Attended some or most of the } \\
\text { time... }\end{array}$ & $1.30,0.15$ to 11.04 & .812 & $0.65,0.21$ to 2.03 & .458 & $0.43,0.14$ to 1.26 & .122 & $0.43,0.14$ to 1.30 & .135 \\
\hline \multicolumn{9}{|l|}{$\begin{array}{l}\text { vs. Always attended before } \\
\text { most recent invitation }\end{array}$} \\
\hline Age (in years) & $1.01,0.95$ to 1.09 & .705 & $0.97,0.92$ to 1.02 & .205 & $0.98,0.93$ to 1.03 & .352 & $0.96,0.92$ to 1.00 & .048 \\
\hline \multicolumn{9}{|l|}{ Decision-making styles } \\
\hline Avoidant score & $1.13,0.99$ to 1.30 & .082 & $0.97,0.89$ to 1.06 & .523 & $0.94,0.87$ to 1.03 & .176 & $0.97,0.89$ to 1.05 & .452 \\
\hline Dependent score & $1.02,0.91$ to 1.14 & .761 & $1.00,0.92$ to 1.09 & .973 & $1.01,0.93$ to 1.09 & .876 & $1.03,0.96$ to 1.11 & .434 \\
\hline Intuitive score & $0.97,0.82$ to 1.13 & .671 & $1.08,0.96$ to 1.21 & .191 & $1.09,0.98$ to 1.22 & .116 & $1.01,0.91$ to 1.12 & .892 \\
\hline Rational score & $1.02,0.86$ to 1.20 & .853 & $0.99,0.88$ to 1.11 & .801 & $0.98,0.88$ to 1.09 & .722 & $1.08,0.97$ to 1.19 & .151 \\
\hline Spontaneous score & $0.92,0.81$ to 1.04 & .169 & $0.99,0.91$ to 1.08 & .861 & $0.98,0.90$ to 0.90 & .653 & $1.03,0.95$ to 1.11 & .528 \\
\hline
\end{tabular}

ORs and $95 \% \mathrm{Cls}$ are per unit increase in the case of continuous variables; $p$-values $<.05$ are in bold

\section{Abbreviations}

ABACUS: Attitudes, Behaviour and Cancer UK Survey; BTEC: Business and Technology Education Council; Cl: Confidence interval; DMS: Decision-making style; GCSE: General Certificate of Secondary Education; NHS: National Health Service; ONC: Ordinary National Certificate; OR: Odds ratio; PAPM: Precaution Adoption Process Model; SD: Standard deviation; SPSS: Statistical Package for the Social Sciences; TNS: Taylor Nelson Sofres; UK: United Kingdom

\section{Acknowledgements}

Not applicable.

\section{Funding}

The current study was supported by a programme grant from Cancer Research UK awarded to Prof Jane Wardle (C1418/A14134). Dr. Jo Waller is supported by a Career Development Fellowship from Cancer Research UK (C7492/A17219). Cancer Research UK was not involved in the design of this study; the collection, analysis, or interpretation of the results; in the writing of the manuscript; or in the decision to submit for publication.

\section{Availability of data and materials}

The data supporting the conclusions of this article are available from the authors, on request.

\section{Authors' contributions}

$A G, C R$, and JW participated in the conception and design of the study, analysis and interpretation of the data, drafting and critical revision of the manuscript, and approved the final version.

\section{Competing interests}

The authors declare that they have no competing interests.

\section{Consent for publication}

Not applicable.

\section{Ethics approval and consent to participate}

Ethical approval was granted by the University College London Research Ethics Committee (5771/002). Participants' completion of the survey constituted consent.

\section{Publisher's note}

Springer Nature remains neutral with regard to jurisdictional claims in published maps and Institutional affiliations.
Received: 22 October 2016 Accepted: 1 April 2017

Published online: 18 April 2017

\section{References}

1. House of Commons Science and Technology Select Committee. National Health Screening. Third Report of Session 2014-15.2014 [cited 2016 Oct 19] Available from: http://www.parliament.uk/business/committees/committeesa-z/commons-select/science-and-technology-committee/inquiries/parliament2010/national-health-screening

2. National Screening Committee. Criteria for appraising the viability, effectiveness and appropriateness of a screening programme. 2015 [cited 2016 Oct 19]. Available from: https://www.gov.uk/government/publications/evidence-reviewcriteria-national-screening-programmes/criteria-for-appraising-the-viabilityeffectiveness-and-appropriateness-of-a-screening-programme

3. General Medical Council. Consent: patients and doctors making decisions together. 2008 [cited 2016 Oct 19]. Available from: http://www.gmc-uk.org/ guidance/ethical_guidance/consent_guidance_index.asp

4. National Breast Screening Programme. NHS Breast Screening: Helping you decide. 2013 [cited 2016 Oct 19]. Available from: https://www.gov.uk/ government/publications/breast-screening-helping-women-decide

5. National Cervical Screening Programme. NHS cervical screening. Helping you decide. [cited 2016 Oct 19]. Available from: https://www.gov.uk/ government/publications/cervical-screening-description-in-brief

6. Bowel Cancer Screening Programme. Bowel cancer screening. The facts [cited 2016 Oct 19]. Available from: https://www.gov.uk/government/ publications/bowel-cancer-screening-benefits-and-risks

7. Forbes $L J$, Ramirez AJ. Expert group on information about breast screening. Offering informed choice about breast screening. J Med Screen. 2014;21: 194-200.

8. Kobayashi LC, Waller J, von Wagner C, Wardle J. A lack of information engagement among colorectal cancer screening non-attenders: crosssectional survey. BMC Public Health BMC Public Health; 2016; 16:659.

9. van Jaarsveld $\mathrm{CH}$, Miles $\mathrm{A}$, Edwards $\mathrm{R}$, Wardle J. Marriage and cancer prevention: does marital status and inviting both spouses together influence colorectal cancer screening participation? J Med Screen. 2006;13:172-6.

10. Stimpson JP, Wilson FA, Watanabe-Galloway S, Peek MK. The effect of marriage on utilization of colorectal endoscopy exam in the United States. Cancer Epidemiol. 2012;36:e325-32.

11. Lo SH, Waller J, Wardle J, von Wagner C. Comparing barriers to colorectal cancer screening with barriers to breast and cervical screening: a population-based survey of screening-age women in great Britain. J Med Screen. 2013:20:73-9.

12. Madlensky L, Esplen MJ, Gallinger S, McLaughlin JR, Goel V. Relatives of colorectal cancer patients: factors associated with screening behavior. Am J Prev Med. 2003;25:187-94. 
13. Rees $G$, Martin PR, MacRae FA. Screening participation in individuals with a family history of colorectal cancer: a review. Eur J Cancer Care (Engl). 2008;17:221-32.

14. Weber MF, Banks E, Ward R, Sitas F. Population characteristics related to colorectal cancer testing in new South Wales, Australia: results from the 45 and up study cohort. J Med Screen. 2008;15:137-42.

15. McLachlan S-A, Clements A, Austoker J. Patients' experiences and reported barriers to colonoscopy in the screening context-a systematic review of the literature. Patient Educ Couns. 2011;86:137-46.

16. Antill YC, Reynolds J, Young MA, Kirk JA, Tucker KM, Bogtstra TL, et al. Screening behavior in women at increased familial risk for breast cancer. Familial Cancer. 2006;5:359-68.

17. Fleming P, O'Neill S, Owens M, Mooney T, Fitzpatrick P. Intermittent attendance at breast cancer screening. J Public health Res. 2013;2:e14.

18. Scott SG, Bruce RA. Decision-making style. The development and assessment of a new measure. Educ Psychol Meas. 1995;55:818-31.

19. Weinstein ND. The precaution adoption process. Health Psychol. 1988;7:355-86.

20. Willis $\mathrm{GB}$, Artino $\mathrm{AR}$. What do our respondents think we're asking? Using cognitive interviewing to improve medical education surveys. J Grad Med Educ. 2013;5:353-6.

21. Office for National Statistics. 2011 Census: Key Statistics for England and Wales, March 2011.2012 [cited 2016 Oct 19]. Available from: http://www.ons. gov.uk/peoplepopulationandcommunity/populationandmigration/ populationestimates/bulletins/2011 censuskeystatisticsforenglandandwales/ 2012-12-11

22. Miles A, Rainbow S, Von Wagner C. Cancer fatalism and poor self-rated health mediate the association between socioeconomic status and uptake of colorectal cancer screening in England. Cancer Epidemiol Biomark Prev. 2011:20:2132-40.

23. Felsen CB, Piasecki A, Ferrante JM, Ohman-Strickland PA, Crabtree BF. Colorectal cancer screening among primary care patients: does risk affect screening behaviour. J Community Health. 2011;36:605-11.

24. Boonyasiriwat W, Hung M, Hon SD, Tang P, Pappas LM, Burt RW, et al. Intention to undergo colonoscopy screening among relatives of colorectal cancer cases: a theory-based model. Ann Behav Med. 2014;47:280-91.

25. Vrinten C, Waller J, Wagner C Von, Wardle J. Cancer fear: facilitator and deterrent to participation in colorectal cancer screening. Cancer Epidemiol Biomark Prev 2015; 24:400-405.

26. van der Heide I, Wang J, Droomers M, Spreeuwenberg P, Rademakers J, Uiters $\mathrm{E}$. The relationship between health, education, and health literacy: results from the Dutch adult literacy and life skills survey. J Health Commun. 2013;18(Suppl 1):172-84.

27. von Wagner C, Semmler C, Good A, Wardle J. Health literacy and self-efficacy for participating in colorectal cancer screening: the role of information processing. Patient Educ Couns. 2009;75:352-7.

28. Entwistle VA, Carter SM, Trevena L, Flitcroft K, Irwig L, McCaffery K, et al. Communicating about screening. BMJ. 2008;337:a 1591.

29. Smith SG, Raine R, Obichere A, Wolf MS, Wardle J, von Wagner C. The effect of a supplementary ('gist-based') information leaflet on colorectal cancer knowledge and screening intention: a randomized controlled trial. J Behav Med. 2015;38:261-72.

30. Ghanouni A, Renzi C, Meisel SF, Waller J. Common methods of measuring 'informed choice' in screening participation: challenges and future directions. Prev Med Rep. 2016;4:601-7.

31. Lo SH, Waller J, Vrinten C, Wardle J, von Wagner C. Self-reported and objectively recorded colorectal cancer screening participation in England. J Med Screen. 2015;23:17-23.

32. Long JS. Regression models for categorical and limited dependent variables. Thousand Oaks: Sage; 1997

\section{Submit your next manuscript to BioMed Central and we will help you at every step:}

- We accept pre-submission inquiries

- Our selector tool helps you to find the most relevant journal

- We provide round the clock customer support

- Convenient online submission

- Thorough peer review

- Inclusion in PubMed and all major indexing services

- Maximum visibility for your research

Submit your manuscript at www.biomedcentral.com/submit
C) Biomed Central 